\title{
Depression in End Stage Renal Disease Patients on Maintenance Hemodialysis at Liaquat University Hospital Hyderabad / Jamshoro
}

\section{Rizwan Channa', Muhammad Ali Suhail' ${ }^{2}$, Narinder Kumar ${ }^{3}$, Muhammad Kaleem $^{4}$, Kamran Ali $^{5}$, Hira Saeed Khan $^{6}$}

1 Assistant Professor, Department of Medicine, SRMC (Suleman Roshan Medical College), Tando Adam Pakistan

1 Data collection, Manuscript writing

Professor, Department of Urology, Peoples University of Medical and Health Sciences for Women, Nawabshah

2 Pakistan

Supervised the project, Proof reading

3 Assistant Professor, Department of Medicine, Bhitai Dental and Medical College Mirpurkhas, Pakistan

3 Statistical analysis

4 Senior Registrar, Department of Medicine, SRMC (Suleman Roshan Medical College), Tando Adam Pakistan

4 Discussion \& References

5 Consultant Physician, CMH Hyderabad

5 Literature review, Data analysis

Assistant Professor, Department of Physiology, Liaquat University of Medical and Health Sciences, Jamshoro

6 Pakistan

Data collection

How to Cite: Channa R, Sohail MA, Khan HS, Shaikh SN, Ansari Z. Depression in End Stage Renal Disease Patients on Maintenance Hemodialysis at Liaquat University Hospital Hyderabad / Jamshoro. APMC 2021;15(1):60-3. DOI: 10.29054/APMC/2021.741
CORRESPONDING AUTHOR

Dr. Rizwan Channa

Assistant Professor, Department of Medicine, BDMC (Bhitai Dental and Medical College),

Mirpurkhas Pakistan

Email:xxx@mail.com

Submitted for Publication: 05-11-2019 Accepted for Publication 03-03-2020

\section{ABSTRACT}

Objective: To determine the depression in end stage renal disease patients on hemodialysis at Liaquat University Hospital. Study Design: Cross sectional study. Settings: Department of Medicine \& Nephrology at Liaquat University Hospital Hyderabad Pakistan. Duration: Six months from February 2015 to January 2016. Methodology: All the Male or Female of age 14-70 years having ESRD patients on maintenance hemodialysis for $>3$ months period were included. Questionnaire proforma was filled and patient who score 5 or more on depression scale were labeled as positive for depression. An informed written consent for the study was obtained from the patients and their relatives. All the data was recorded on a pre-designed proforma. Data was analyzed by using SPSS version 20. Results: The mean age of patients was $52.21 \pm 7.90$ years. There were $69.9 \%$ males and $30.1 \%$ female patients. Out of all $35.8 \%$ patients were employed while $64.2 \%$ patients were unemployed. Most of the patients $92.3 \%$ were married and $7.7 \%$ were unmarried. The depression in patients with end stage renal disease was found in $47.2 \%$ patients. Conclusion: The frequency of depression in end stage renal disease patients on hemodialysis at Liaquat University Hospital was found to be higher as $47.2 \%$. However, there is need to involve the expert Psychiatrists to cope with this higher problem of depression to improve their quality of life by giving them additional anti-depressant along with hemodialysis.

Keywords: Renal failure, Dialysis, Quality of life, Stress and depression.

\section{INTRODUCTION}

The End-stage renal disease (ESRD) is a serious public health problem, ${ }^{1}$ with a crucial effect on the quality life of patients. After hypertension, the second most prevalent psychiatric condition in ESRD subjects is depression and is regarded as a co-morbid diagnosis within this group. 4,5 Not just patients with hemodialysis, as well as their caregivers, are negatively affected by stress. ${ }^{6}$ Despite major recent improvements in therapy, mal-compliance and psychological issues, such as behavioral dysfunction, anxiety and depression are prevalent in end-stage kidney disease patients with hemodialysis.7 Studies reporting the incidence of depression in dialysis patients from 10 percent to 60 percent are highly variable, based on the study population's demographic and evaluation tools used. 8-11 The patients and their whole family are frequently stressed by therapy and illness because of their life-long dialysis; ${ }^{12,13}$ especially if the person is primary caregiver of the family. The incidence of depression among ESRD cases is largely unclear; it has played a crucial role in advancing the psychological evaluation of patients. Depression evaluation typically includes self-screening tools and the application of clinical diagnosis interviews, both are administered under diagnostic classification schemes like the International Classification of Diseases (ICD-10) and the Diagnostic and Statistical Manual-IV (DSM-IV).15 Typically, screening devices are used to calculate the symptoms of a patient in terms of depressive symptoms as serious, moderate or mild. The precision of screening devices is restricted in chronically ill populations, however, because of' criterion contaminations' that overlap somatic symptoms related to the medical condition and symptomatology of depression. ${ }^{16}$ It is a subject of much discussion that whether or not diagnostic and screening systems should eliminate 
overlapping symptoms, and that there is insufficient evidence to propose that depression-related somatic and cognitive symptoms can be distinguished from behavioral and affective components. Highly prevalent depression is linked to poor quality of life and the elevated mortality rate in adults having chronic kidney disease, particularly among those having end-stage renal disease. ${ }^{17}$ However present study has been conducted to estimate the burden of depression in ESRD patient in our population.

\section{METHODOLOGY}

Study Design: Cross sectional study.

Settings: Department of Medicine \& Nephrology at Liaquat University Hospital Hyderabad Pakistan.

Duration: One year from February 2015 to January 2016.

Sample Technique:

Sample Size:

Inclusion Criteria: All the Male or Female of age 14-70 years having ESRD patients on maintenance hemodialysis for $>3$-month period were included.

Exclusion Criteria: All the patients who were mentally disoriented, unconscious or unwilling to participate, history of any Psychotic drug disorder, current treatment with antidepressant medication, language impairment severe sufficient to avoid valid neuropsychiatric appraisal and patients of acute renal failure on hemodialysis were excluded.

Data Collection Procedure: Patient who score 5 or more according to depression scale, were labeled as positive for depression. ESRD is the last stage of chronic renal disease in which glomerular filtration rate (GFR) is below $15 \mathrm{ml} / \mathrm{min} / 1.73 \mathrm{~m}^{2}$, it is irreversible, uncontrollable by conservative administration alone, and needs dialysis or renal transplant to survive. Maintenance Hemodialysis is the state of being maintained on Hemodialysis throughout life in order to save life of ESRD patient. At least twice hemodialysis in a week required. The data was documented on a pre-designed proforma and then it was analyzed by SPSS (statistical program) version 16.0.

\section{RESULTS}

The mean age of patients was 52.21 \pm 7.90 years with minimum and maximum ages of 28 and 68 years. Table 1

Table 1: Descriptive statistics of age

\begin{tabular}{|l|c|}
\hline Mean & 52.21 \\
\hline Std. Deviation & 7.90 \\
\hline Range & 40.00 \\
\hline Minimum & 28.00 \\
\hline Maximum & 68.00 \\
\hline
\end{tabular}

There were $9.9 \%$ males and $30.1 \%$ female patients, with male to female ratio as $2.32: 1$. Out of all $27.2 \%$ patients were uneducated, $38.2 \%$ had primary had primary level education, $20.3 \%$ had matric level education and $14.2 \%$ patients showed their education level of intermediate. A total of $35.8 \%$ patients were employed while $64.2 \%$ patients were unemployed. $33.7 \%$ patients belonged to lower socioeconomic status, $66.3 \%$ belonged to middle and none of the patients was from higher socio-economic status. There were $92.3 \%$ patients who were married while $7.7 \%$ patients were unmarried. Table 2

Table 2: Gender distribution of patients $(n=246)$

\begin{tabular}{|l|c|c|c|}
\hline \multirow{2}{*}{ Gender } & Male & Frequency & Percent \\
\hline \multirow{4}{*}{ Education } & Female & 172 & 69.9 \\
\cline { 2 - 4 } & No education & 74 & 30.1 \\
\cline { 2 - 4 } & Primary & 67 & 27.2 \\
\cline { 2 - 4 } & Matric & 50 & 38.2 \\
\cline { 2 - 4 } & Intermediate & 35 & 20.3 \\
\hline \multirow{2}{*}{ Employment } & Employed & 88 & 14.2 \\
\cline { 2 - 4 } & Unemployed & 158 & 64.8 \\
\hline \multirow{2}{*}{$\begin{array}{l}\text { Socio economic } \\
\text { status }\end{array}$} & Lower & 83 & 33.7 \\
\cline { 2 - 4 } & Middle & 163 & 66.3 \\
\cline { 2 - 4 } & Higher & 0 & $0 \%$ \\
\hline \multirow{2}{*}{ Marital Status } & Married & 227 & 92.3 \\
\cline { 2 - 4 } & Unmarried & 19 & 7.7 \\
\hline
\end{tabular}

As per assessment of depression, most of the patients were feeling sad or empty, restlessness, lethargy, worthlessness as showed in table 3.

Table 3: Descriptive statistics for "Feel Sad or empty" $(\mathrm{n}=246)$

\begin{tabular}{|c|c|c|c|}
\hline & & Frequency & Percent \\
\hline \multirow{2}{*}{ Feel Sad or empty } & Yes & 194 & 78.9 \\
\hline & No & 52 & 21.1 \\
\hline \multirow{2}{*}{$\begin{array}{l}\text { Loss of interest in activates } \\
\text { previously enjoyed }\end{array}$} & Yes & 81 & 32.9 \\
\hline & No & 165 & 67.1 \\
\hline \multirow{2}{*}{$\begin{array}{l}\text { Weight loss } 5 \% \text { when not } \\
\text { dieting }\end{array}$} & Yes & 91 & 37 \\
\hline & No & 155 & 63 \\
\hline \multirow{2}{*}{$\begin{array}{l}\text { Weight gain } 5 \% \text { when not } \\
\text { dieting }\end{array}$} & Yes & 69 & 28 \\
\hline & No & 177 & 72 \\
\hline \multirow{2}{*}{ Late onset sleep } & Yes & 92 & 37.4 \\
\hline & No & 154 & 62.6 \\
\hline \multirow{2}{*}{$\begin{array}{l}\text { Feels un-fresh in the } \\
\text { morning }\end{array}$} & Yes & 96 & 39 \\
\hline & No & 150 & 61 \\
\hline \multirow{2}{*}{$\begin{array}{l}\text { Feelings of restlessness or } \\
\text { being slow down }\end{array}$} & Yes & 114 & 46.3 \\
\hline & No & 132 & 53.7 \\
\hline \multirow{2}{*}{ Loss of energy (Lethargy) } & Yes & 91 & 39 \\
\hline & No & 150 & 61 \\
\hline \multirow{2}{*}{ Feelings of worthlessness } & Yes & 103 & 41.9 \\
\hline & No & 143 & 58.1 \\
\hline \multirow{2}{*}{$\begin{array}{l}\text { Diminished ability to } \\
\text { concentrate }\end{array}$} & Yes & 94 & 38.2 \\
\hline & No & 152 & 61.8 \\
\hline \multirow{2}{*}{ Recurrent thoughts of death } & Yes & 98 & 39.8 \\
\hline & No & 148 & 60.2 \\
\hline
\end{tabular}


The frequency of depression in patients with end stage of renal disease was found in 116(47.2\%) patients. Table 4

Table 4: Descriptive statistics for "Frequency of depression"

\begin{tabular}{|c|c|c|c|}
\hline \multicolumn{2}{|c|}{} & Frequency & Percent \\
\hline \multirow{2}{*}{ Depression } & Yes & 116 & 47.2 \\
\cline { 2 - 4 } & No & 130 & 52.8 \\
\hline \multicolumn{2}{|c|}{ Total } & 246 & 100.0 \\
\hline
\end{tabular}

\section{DISCUSSION}

End-stage kidney disease (ESRD) significantly affects the life of patients. Multiple loss experiences, including time, family role, renal function, sexual function, job role and mobility, have a significant effect on patients ' lives.17-19 Other stressors including drug impacts, nutritional limitations, anxiety of death and therapy dependence, may exacerbate feelings of losing control and affect quality of life. Depression has been commonly reported to be the most prevalent psychopathological disorder among ESRD patients. ${ }^{20}$ The patients' mean age in this study was $52.21 \pm 7.90$ years, while another study reported the similar mean age i.e., $54 \pm 15$ years. ${ }^{21}$ In current study there were $172(69.9 \%)$ males and 74(30.1\%) female patients. However, the predominance of male gender is also supported by other studies.22,23 We also found there were $67(27.2 \%)$ uneducated, $94(38.2 \%)$ had primary, $50(20.3 \%)$ had matric and $35(14.2 \%)$ patients had intermediate education. A total of $88(35.8 \%)$ patients were employed while $158(64.2 \%)$ patients were unemployed. According to socio economic status, $83(33.7 \%)$ patients belonged to lower, 163(66.3\%) belonged to middle and none of the patients was from higher socio-economic status. The lower socioeconomic status has been identified more prevalent in ESRD. ${ }^{24,25}$ Although prominent, depression quite often remains unnoticed in this patient group, reflecting an absence of scheduled psychological evaluation. The effects of avoiding depression among subjects with dialysis may be significant. Comorbid depressive diseases worsen the effect of chronic diseases and boost the use of healthcare facilities and functional disability. ${ }^{18}$ Depression is also reported to be common in patients with long-term dialysis and related to hospitalization and death. It is not evident, whether depression occurs at all phases of chronic renal illness or emerges following initiation of dialysis therapy. ${ }^{26}$

Fresh studies have concentrated on depression-related high incidence in CKD patients. The techniques used to assess depression and distinctions between both the clinical depression and the appearance of the symptoms of depression are essential to comprehend. It is well documented that depressive symptoms and clinical depression are associated with a multitude of results. Several recent studies in individuals with CKD have investigated non-pharmacological and pharmacological methods for treating depressive symptoms. It needs to be determined that how these interventions affect mortality and morbidity, hospitalizations, expenses, and fitness-related measures of quality of life among these patients. ${ }^{27} \mathrm{~A}$ study found that in patients with chronic kidney disease depression is more prevalent, influencing around $20 \%$ of cases before the dialysis begins. ${ }^{26}$ Another study gave the similar statistics with $95 \% \mathrm{CI}, 5 \%$ bond on error and based on least frequent proportion of depression in end-stage renal disease (ESRD) patients on dialysis is reported $20 \% .^{28}$ But in the present study we found the frequency of depression in patients with end stage renal disease was found in $116(47.2 \%)$ patients which is comparably higher frequency of depression as compare to other studies. ${ }^{26,28}$ In addition, the use of unique self-report surveys in different studies has probably led to variable measurements (between 15\% and $60 \%$ ) of the incidence of depression among ESRD cases. ${ }^{29}$ The absence of reliability in these studies could also reflect distinct comorbid diseases, populations evaluated at different occasions following maintenance dialysis treatment, and various baseline features of sample population..$^{27}$

\section{CONCLUSION}

The frequency of depression in end stage renal disease patients on hemodialysis at Liaquat University Hospital is quite higher i.e., up to $47.2 \%$. So, we need to involve some experts from Psychiatry department to cope with this higher problem of depression. We can improve the patients' quality of life by giving them additional antidepressant along with hemodialysis.

\section{LIMITATIONS}

Small sample size and single center study depression in patients with ESRD did not analyzed according to socioeconomic burden, satisfaction regarding treatment and staff behaviors and other socio-demographic factors.

\section{SUGGESTIONS / RECOMMENDATIONS}

More research is needed to identify depression in patients with ESRD using different, high sensitive and specific tools so that we can later identify the reasons, etiology and risk factors of depression in these patients.

\section{CONFLICT OF INTEREST / DISCLOSURE} None.

\section{REFERENCES}

1. García-García G, García-Bejarano H, Breien-Coronado H, PerezCortez G, Pazarin-Villaseñor L, de la Torre-Campos L, AlcantarVallin L. End-stage renal disease in Mexico. InChronic kidney disease in disadvantaged populations 2017;1 (pp. 77-83).

2. Chilcot J, Wellsted D, Silva-Gane D, Farrington K. Depression on dialysis. Nephron Clinical Practice. 2008;108(4):c256-c64. 
3. Szeifert L, Molnar MZ, Ambrus C, Koczy AB, Kovacs AZ, Vamos $\mathrm{EP}$, et al. Symptoms of depression in kidney transplant recipients: a cross-sectional study. American Journal of Kidney Diseases. 2010;55(1):132-40.

4. Kimmel PL, Peterson RA. Depression in end-stage renal disease patients treated with hemodialysis: tools, correlates, outcomes, and needs. Seminars in dialysis. 2004;18:91-7.

5. Anees M, Barki H, Masood M, Ibrahim M, Mumtaz A. Depression in hemodialysis patients. Pak J Med Sci. 2008;24(4):560-5.

6. Saeed Z, Ahmad A, Shakoor A, Ghafoor F, Kanwal S. Depression in patients on hemodialysis and their caregivers. Saudi Journal of Kidney Diseases and Transplantation. 2012;23(5):946-52.

7. Khan MA, Ahmad M. Anxiety, depression and cognitive changes in patients on hemodailysis. PAFMJ. 2012;6(2):442-6.

8. Cukor D, Peterson RA, Cohen SD, Kimmel PL. Depression in endstage renal disease hemodialysis patients. Nature Clinical Practice Nephrology. 2006;2(12):678-87.

9. Hedayati SS, Finkelstein FO. Epidemiology, diagnosis, and management of depression in paᄀtients with C. Am J Kidney Dis 2009;54:741-52.

10. Watnick S, Kirwin P, Mahnensmith R, Concato J. The prevalence and treatment of depression among patients starting dialysis. American Journal of Kidney Diseases. 2003;41(1):105-10.

11. Tyrrell J, Paturel L, Cadec B, Capezzali E, Poussin G. Older patients undergoing dialysis treatment: cognitive functioning, depressive mood and health-related quality of life. Aging \& mental health. 2005;9(4):374-9.

12. Tong A, Sainsbury P, Craig JC. Support interventions for caregivers of people with chronic kidney disease: a systematic review. Nephrology Dialysis Transplantation. 2008;23(12):3960-5.

13. Belasco A, Barbosa D, Bettencourt AR, Diccini S, Sesso R. Quality of life of family caregivers of elderly patients on hemodialysis and peritoneal dialysis. American Journal of Kidney Diseases. 2006;48(6):955-63.

14. Schneider RA. Fatigue among caregivers of chronic renal failure patients: A principal components analysis. Nephrology nursing journal. 2003;30(6):629-36.

15. Belasco AG, Sesso R. Burden and quality of life of caregivers for hemodialysis patients. American Journal of Kidney Diseases. 2002;39(4):805-12.

16. Smyth R. Depression in physical illness. JR Coll Physicians Edinb. 2009;39:337-42.

17. Shirazian S, Grant CD, Aina O, Mattana J, Khorassani F, Ricardo AC. Depression in chronic kidney disease and end-stage renal disease: similarities and differences in diagnosis, epidemiology, and management. Kidney international reports. 2017;1;2(1):94-107.

18. Watnick S, Wang P-L, Demadura T, Ganzini L. Validation of 2 depression screening tools in dialysis patients. American Journal of Kidney Diseases. 2005;46(5):919-24.

19. Kimmel PL, Weihs K, Peterson RA. Survival in hemodialysis patients: the role of depression. Journal of the American Society of Nephrology. 1993;4(1):12-27.

20. Chilcot J, Wellsted D, Farrington K. Screening for depression while patients dialyse: an evaluation. Nephrology Dialysis Transplantation. 2008;23(8):2653-9.

21. Abdel-Kader K, Unruh ML, Weisbord SD. Symptom burden, depression, and quality of life in chronic and end-stage kidney disease. Clinical Journal of the American Society of Nephrology. 2009;4(6):1057-64.

22. Sumanathissa M, de Silva VA, Hanwella R. Prevalence of major depressive episode among patients with pre-dialysis chronic kidney disease. The International Journal of Psychiatry in Medicine. 2011;41(1):47-56.

23. Kalender B, Corapcioglu Ozdemir A, Koroglu G. Association of depression with markers of nutrition and inflammation in chronic kidney disease and end-stage renal disease. Nephron Clinical Practice. 2005;102(3-4):c115-c21.

24. Young EW, Mauger EA, Jiang K-H, Port FK, Wolfe RA. Socioeconomic status and end-stage renal disease in the United States. Kidney international. 1994;45(3):907-11.

25. Byrne C, Nedelman J, Luke RG. Race, socioeconomic status, and the development of end-stage renal disease. American Journal of Kidney Diseases. 1994;23(1):16-22.

26. Shirazian S, Grant CD, Aina O, Mattana J, Khorassani F, Ricardo AC. Depression in chronic kidney disease and end-stage renal disease: similarities and differences in diagnosis, epidemiology, and management. Kidney international reports. 2017;2(1):94-107.

27. Hedayati S, Bosworth H, Kuchibhatla M, Kimmel P, Szczech L. The predictive value of self-report scales compared with physician diagnosis of depression in hemodialysis patients. Kidney international. 2006;69(9):1662-8.

28. Cukor D, Peterson RA, Cohen SD, Kimmel PL. Depression in endstage renal disease hemodialysis patients. Nature clinical practice Nephrology. 2006;2(12):678-87.

29. Hedayati SS, Finkelstein FO. Epidemiology, diagnosis, and management of depression in patients with CKD. American journal of kidney diseases: the official journal of the National Kidney Foundation. 2009;54(4):741-52. 